\title{
Assessment of scour development at a deep-water marine jetty using 3d computational fluid dynamics
}

Richard Whitehouse and Sébastien Bourban

Reproduced from a paper published in:

Proceedings of the Fifth International Conference on Scour and Erosion (ICSE-5), American Society of Civil Engineers, November 7-11, 2010

San Francisco, California 



\title{
ASSESSMENT OF SCOUR DEVELOPMENT AT A DEEP-WATER MARINE JETTY USING 3D COMPUTATIONAL FLUID DYNAMICS
}

\author{
Richard Whitehouse and Sébastien Bourban \\ HR Wallingford, Howbery Park, Wallingford, Oxfordshire, OX10 8BA, UK. \\ Email: r.whitehouse@hrwallingford.co.uk, s.bourban@hrwallingford.co.uk \\ Tel: +1491835381
}

\section{Key Words}

\begin{abstract}
To assess the interaction of the tidal flow with a deep-water marine jetty, Computational Fluid Dynamics (CFD) was used to predict flow patterns for fast flood and ebb tide conditions both without and with the jetty in place. The modelled area covered three square kilometres of coastal bathymetry around the jetty head, with pile diameters of the order of one metre and water depths ranging from $3 \mathrm{~m}$ to $45 \mathrm{~m}$. The predicted changes in velocity and bed shear stress distribution were used to explain the observed local bed level changes at this site over a period of three years.
\end{abstract}

\section{INTRODUCTION}

To understand the interaction of strong tidal flow with a deep-water jetty structure, an analysis of the current patterns was completed with a three dimensional Computational Fluid Dynamics (CFD) model. This paper describes an assessment of the modelling and comparison with the seabed changes. To take account of the local influences and to cover the far field, the modelled area covered three square kilometres. Detailed bed level surveys were carried out before construction of the jetty was started and once it was completed, and has shown changes. This paper describes the modelling approach, the observed bed level changes, and the analysis of the flow and bed shear stress distributions. The model results provide a systematic basis for understanding the observed bed level changes at the jetty site.

\section{THE JETTY AND THE MARINE ENVIRONMENTAL CONDITIONS}

The 2.5 kilometre long jetty is supported by circular steel piles of varying diameter with vertical and raker piles (varying between $1.2 \mathrm{~m}$ and $1.4 \mathrm{~m}$ diameter) at various angles and orientations (Figure 1). The T-head is $2.5 \mathrm{~km}$ from the shore and the seawards $0.25 \mathrm{~km}$ is situated in deep water with a water depth to mean tide level of $21.6 \mathrm{~m}$. The bathymetry before jetty construction is shown in Figure 2.

Tidal current data offshore of the jetty head during construction showed that the flood tide currents at the surface can reach speeds of $2.8 \mathrm{~ms}^{-1}$, or higher, and that the ebb tide currents can be as large as $1.75 \mathrm{~ms}^{-1}$. Figure 3 shows the nature of the flood tide flow interaction with the mooring dolphins and the generation of turbulent wakes. As expected depth-averaged flows were somewhat smaller than the surface values. The duration of the flood and ebb tide streams are approximately equal and hence the tide has a marked flood-ebb asymmetry (flood/ebb ratio =1.6). The directions of the near surface current vectors are aligned slightly offshore on the north going flood and slightly inshore on the ebb. Representative values of water density and kinematic viscosity are $1023 \mathrm{kgm}^{-3}$ and $0.95610^{-6} \mathrm{~m}^{2} \mathrm{~s}^{-1}$, respectively. 


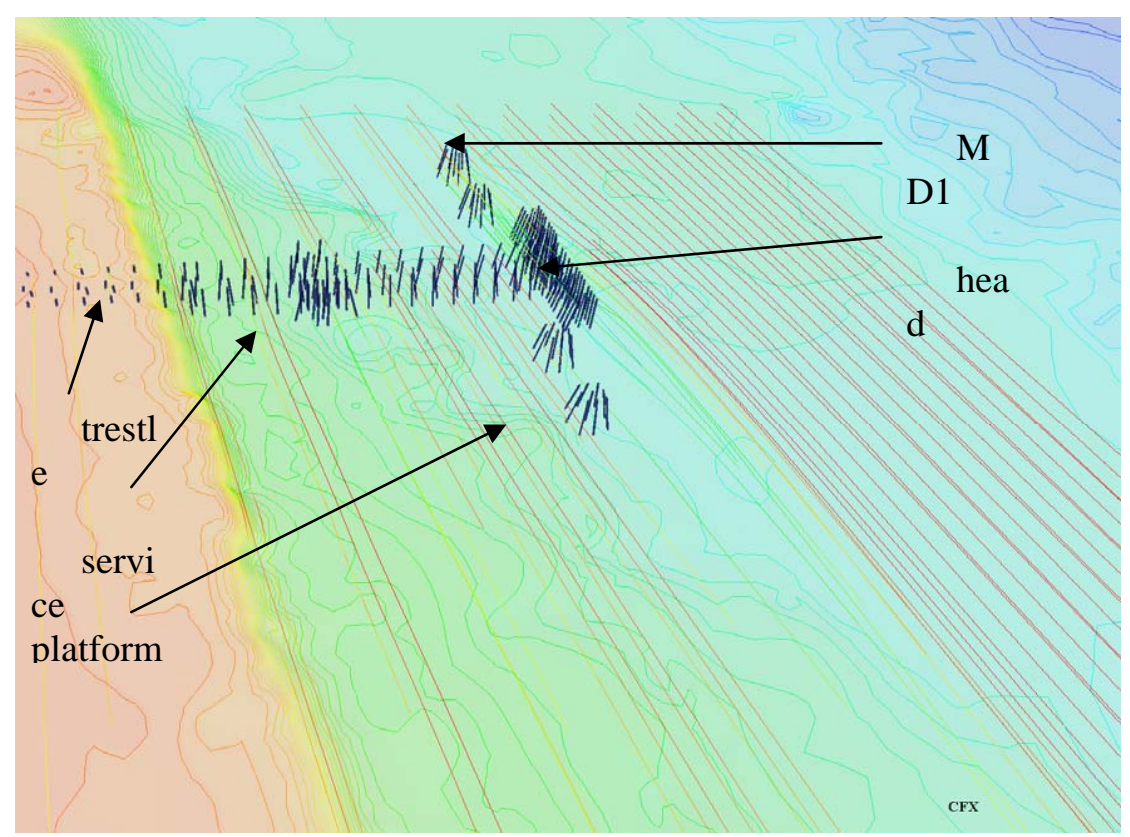

Figure 1. Jetty pile layout showing trestle, service platform, jetty head, and the four pile clusters for the mooring dolphins (MD1 to 4). Modelled flood tide streamlines are shown passing from top to bottom of the figure.

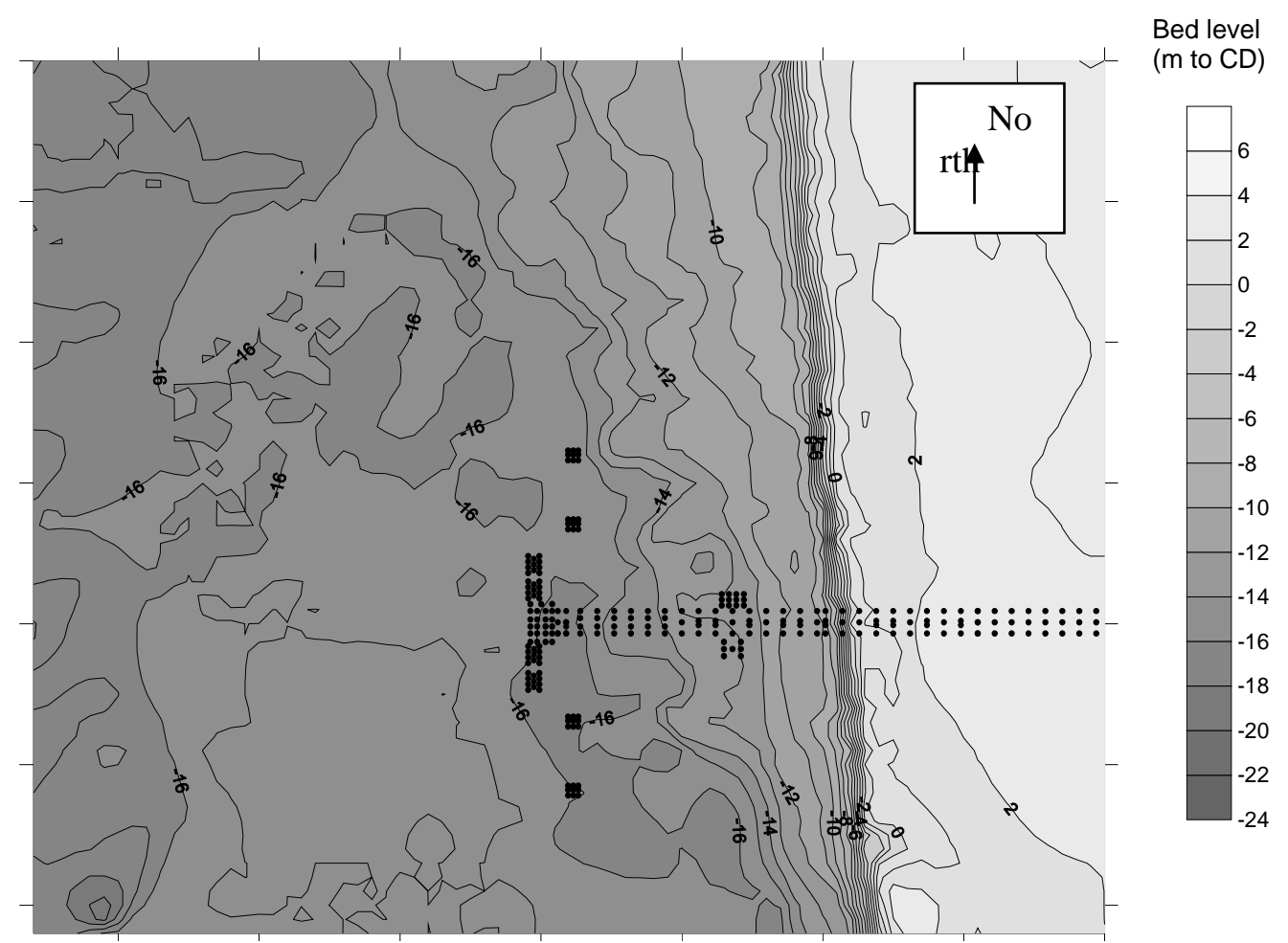

Figure 2. Seabed bathymetry in metres below Chart Datum pre-construction survey axes tick-marks at $100 \mathrm{~m}$ intervals and future installed pile locations shown. 


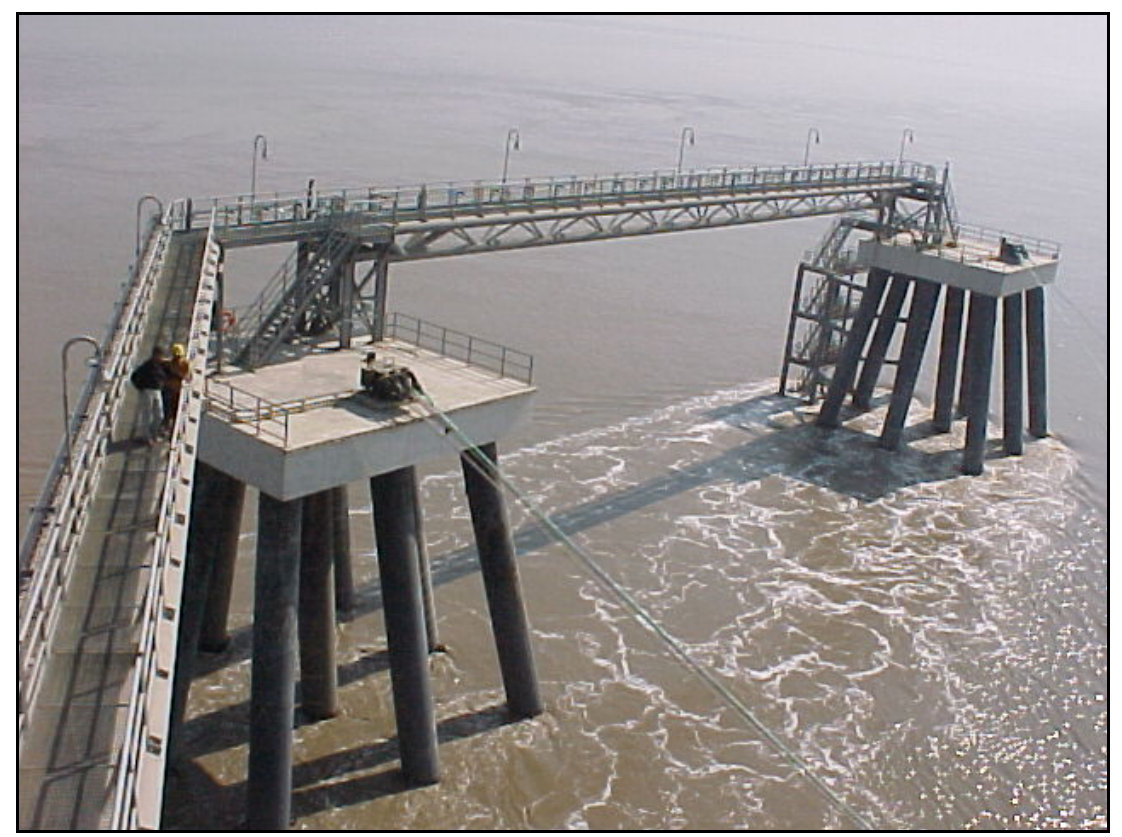

Figure 3. Tidal flow around mooring dolphins at the jetty (flow from right to left).

\subsection{SEDIMENT MOBILITY}

The sediment was loose to medium dense and dense, dark brown/grey, slightly silty to very silty, fine sand. The typical near surface particle size distributions from borehole analysis for the $10^{\text {th }}, 50^{\text {th }}$ and $90^{\text {th }}$ percentile grain sizes were $0.08 \mathrm{~mm}, 0.17 \mathrm{~mm}$ and $0.25 \mathrm{~mm}$, respectively, and the median grain size $d_{50}$ was uniform in the top $10 \mathrm{~m}$ of the core. The threshold depthaveraged tidal current speed for sediment movement was $0.44 \mathrm{~ms}^{-1}$ and hence tidal flow produces strong transport. Since the duration of the flood and ebb flow is approximately equal, the flow asymmetry produces a net sediment transport in the direction of the flood tide.

Bedforms at the jetty included large sandwaves and smaller, irregular, bed waves, furrows and ripples, with the sandwaves indicating predominantly northward transportation of sediments; in agreement with the flow asymmetry. The larger sandwaves had wavelengths of 80 $\mathrm{m}$ to $120 \mathrm{~m}$ and heights of $1 \mathrm{~m}$ to $2.5 \mathrm{~m}$ and the sandwave field extended in the flood current direction away from the jetty axis. The post-construction survey also showed the presence of sandwaves with the jetty in place.

\section{OBSERVED SEABED MORPHOLOGICAL CHANGES}

The pre-construction survey (Figure 2) showed the seabed contours were sinuous and quite closely spaced in the jetty area and oriented closely parallel to the tide axis. There was a localised depression in the seabed at the proposed location of the jetty head (the positions of the jetty piles at trestle level are marked in Figure 2). A post-construction survey taken three years later provided a comparable coverage apart from close in to the jetty where it was more difficult to manoeuvre the survey vessel. The survey showed significant changes in the seabed in the vicinity of the jetty.

The analysis of bed level changes was undertaken using SURFER ${ }^{\mathrm{TM}}$ (see Figure 7). The changes that have taken place were characterised by overall erosion (deepening) of the seabed, by around $2 \mathrm{~m}$ to $3 \mathrm{~m}$ offshore of the jetty, and a localised pattern of erosion under and around the jetty trestle. The areas of erosion were in a zone north (downstream in the flood tide direction) of the jetty trestle, to a maximum total scour depth of $9.5 \mathrm{~m}$, and an area adjacent to 
the jetty head, to a maximum total scour depth of $8.5 \mathrm{~m}$; including changes that would have occurred naturally in seabed levels. In contrast there is also an area downstream of the jetty head in the flood tide direction where the bed level change was negligible, and hence siltation was understood to have taken place.

\section{COMPUTATIONAL MODELLING}

The mathematical Computational Fluid Dynamics (CFD) code CFX-5 ${ }^{\mathrm{TM}}$ from AEA Technology (now with ANSYS) was used and the submerged elements of the jetty were represented. The model was filled in with a 3D-mesh of combined tetrads, pyramids and prisms of variable sizes depending on the place of interest. The mesh size varied from $0.5 \mathrm{~m}$ wide per element in the proximity of the jetty to $40 \mathrm{~m}$ away from the jetty. The mesh was refined around the piles, at the seabed and at the submarine slope. A $0.1 \mathrm{~m}$ thick layer of prisms was used adjacent to the seabed to enable a good representation of the friction/turbulent boundary condition. The flow structure and associated turbulence in 3-dimensions was achieved using a k- $\varepsilon$ turbulence closure as this offered the best compromise between complexity and run time considerations over the large area that was to be modelled. Because of the deep water a rigid-lid assumption was made and the emphasis placed on obtaining the flow distribution and turbulent stresses near the seabed. On the seabed, the turbulent layer was modelled through a friction law calculation using a bed roughness length of $6 \mathrm{~mm}$. This value is appropriate for rippled sand (Soulsby, 1997). The hydraulic roughness of the steel piles was simulated with a value of ???? DEFAULT.

The jetty was placed within an accurate representation of the pre-construction seabed bathymetry over the whole model domain. The water depth varied from $3 \mathrm{~m}$ in the shallow eastern area to $45 \mathrm{~m}$ in the offshore part of the model domain (Figure 2). The area covered by the model domain extended $2 \mathrm{~km}$ from north to south and $1.5 \mathrm{~km}$ from east to west. The size of the computational domain was chosen so that the boundaries were sufficiently far from the jetty such that flow in and around the jetty was free from any boundary wall effects.

\subsection{TIDAL SCENARIOS}

Boundary conditions were set in order to obtain the required peak velocity at the head of the jetty. Firstly, an incoming mass flow rate was calibrated for both the ebb and the flood scenarios, and secondly a spatially variable velocity profile was set according to the calibrated mass flow and the bathymetry. The profile was weighted with the square root of the local water depth, which is a common approximation used in hydrodynamic modelling of coasts and estuaries. The predicted flow speeds and headings at the jetty head were close to the observed values, i.e. speeds within $10 \%$ of the measured values. By comparing the results obtained for the model with the jetty with those for the model without the jetty, using similar mesh geometry, the influence on the flow could be determined directly.

\section{MODEL RESULTS AND COMPARISON WITH OBSERVED BED LEVEL CHANGES}

\subsection{GENERAL CONSIDERATIONS WITH AND WITHOUT THE JETTY}

The submarine slope and the gradual rise in the bathymetry beyond the jetty in the flood tide direction exert a controlling influence on the flow, e.g. see flood tide streamlines in Figure 1 and flow vectors in Figure 4 . The presence of the jetty and its variable structure density impart nonuniformity on the pattern of velocity and shear stress.

With the jetty in place, on the ebb flow, the water flow was parallel to the jetty head offshore from the service platform, and at a slight angle under the approach trestle where there was local acceleration around and through the piles. Also there was acceleration of the flow inshore of the 
control room. On the flood tide there was a marked deviation of the flow direction immediately offshore of the jetty head and acceleration in the flow (Figure 4). The flow velocity is considerably reduced to the lee of the service platform, the mooring dolphins and the control room. There is local flow acceleration around and through the trestle between these structures and zones of shear generating turbulence.

The gradual rise in the bathymetry north of the jetty (Figure 2) produced a vertical contraction of the flow under flood conditions and extension under ebb conditions. As a result, the velocity and, therefore, the shear stress north of the jetty alignment are greater on the flood tide than on the ebb tide. In addition, as the flow speed on the flood tide was much larger than the ebb, and this translates to the shear stress acting on the seabed, there was an asymmetric pattern in the flood and ebb flow fields, turbulence, shear stresses and associated sediment transport.

\subsection{FLOOD FLOW WITH AND WITHOUT THE JETTY}

In terms of near-bed velocity profiles the most significant influence is the appearance of two shadow areas in lee of the jetty head and mooring dolphins 3 and 4 and the service platform piles. The results obtained for the flood conditions with and without the jetty at the offshore (open) and incoming flow boundaries are similar. The influence of the jetty on bed shear stresses is noticeable around the head and north of the jetty (Figure 5).

In addition to creating shadow areas, the jetty tends to decelerate the approaching flow, redirecting it offshore (Figure 1). As a result, the northwards increase in shear stress values produced by the gradual rise of the bathymetry is diminished since less flows pass through the jetty structure. However, two bands of high velocity, turbulent shear and shear stress are evident (1) extending to the north of the trestle between the service platform and the control room, and (2) between the control room and the toe of the submerged cliff.

Finally, adjacent to the jetty head just offshore, the surface velocity profile has been greatly altered. A strong acceleration in the surface and nearbed flow is predicted with non-symmetry to the north (adjacent to mooring dolphins 3 and 4). This zone of acceleration on the flood tide occurs at a similar location to that produced on the ebb (not shown). 


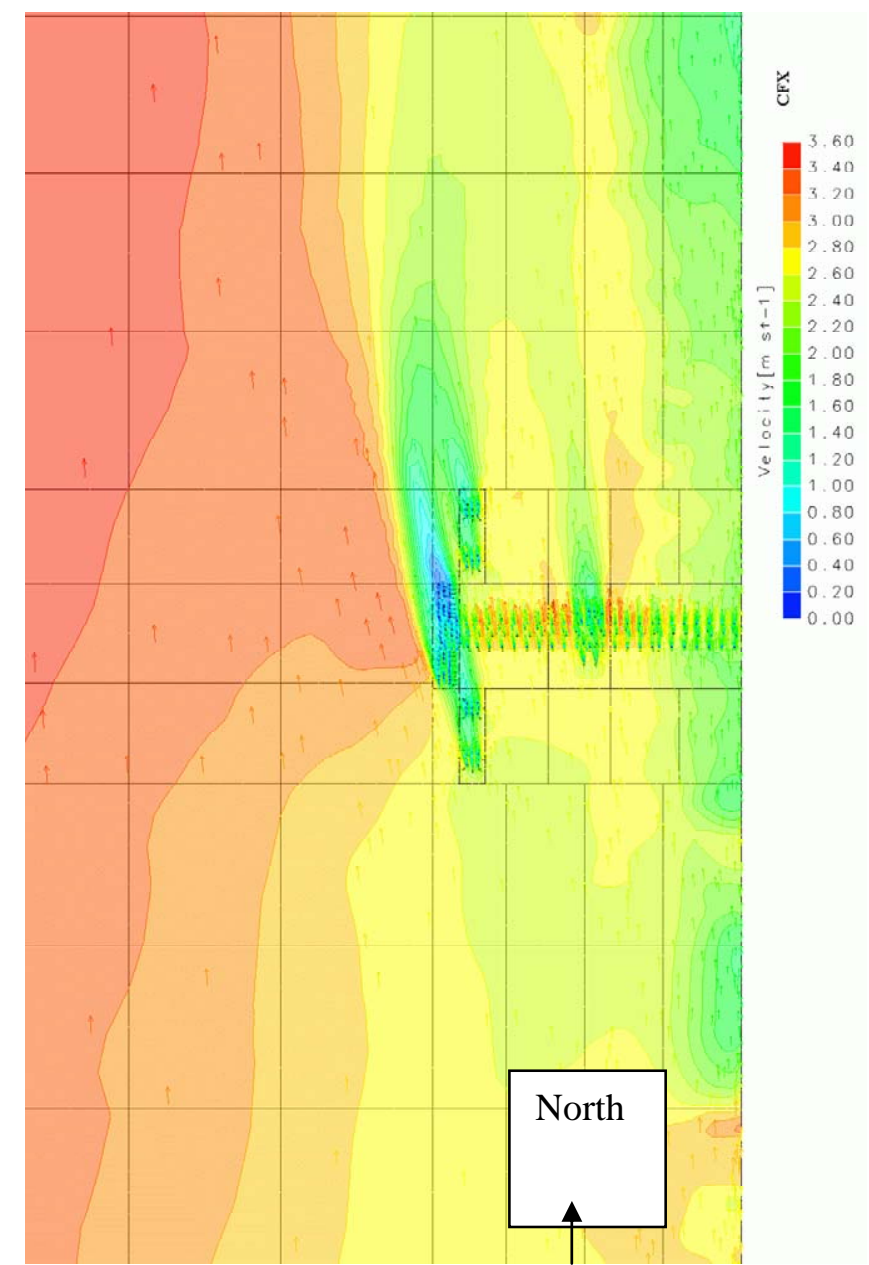

Figure 4. CFX model output for surface current speed contoured with some vectors in $\mathrm{ms}^{-1}$ on flood tide.

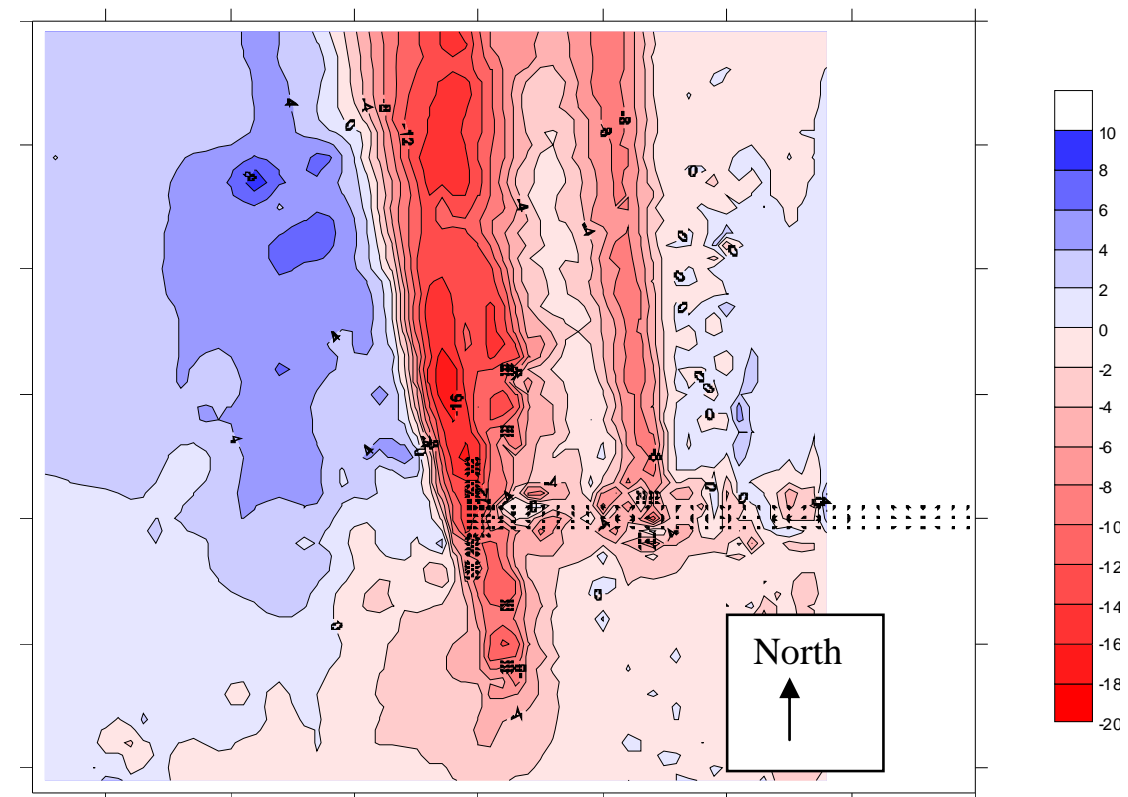

Figure 5. Difference in bed shear stress $\mathrm{Nm}^{-2}$ on flood tide (axes tick-marks $100 \mathrm{~m}$ spacing). 
In terms of shear stress profiles (see Figure 5), the jetty produces four areas of influence (positive values are increased):

$>$ An area of increased shear stress, offshore of the jetty head and increasing in a north northwesterly direction, and inshore of the service platform

$>$ An area of decreased shear stress, north of the jetty head and of the service platform (due to the flow shadow areas)

$>$ An area of decreased shear stress south of the trestle structure (due to deceleration of the approach flow)

$>$ An area of relative decrease in shear stress, in between the service platform and the jetty head and between the service platform and the coast. However, the value of bed shear stress in this area is still high enough to cause significant sediment transport

On the ebb tide similar, but less strong patterns were observed in terms of near-bed velocity distributions.

\section{DISCUSSION}

\subsection{ASSESSMENT OF FLOW SHELTERING AND "BLOCKAGE" EFFECTS}

The influence of the jetty on the bed shear stress distribution has been shown in Figure 5. Considering the influence for both flood and ebb, there are three observations that can be made:

$>$ There is an increase of the velocity field (therefore of the shear stress) at the offshore side of the jetty head

$>$ Mooring dolphins 3 and 4 are exposed to the full strength of the tidal flow on both flood and ebb

$>$ Mooring dolphins 1 and 2 and the jetty head tend to shelter each other depending on the direction of the flow

Considering the differences between flood and ebb tides, the ebb flow passes through the structure while the flood flow tries to avoid the structure. This is caused by the differences in flow speed and the "blockage" to the flow provided by the jetty. The slight variations in the flood and ebb flow directions combine with the orientation of the pile rows under the jetty head to provide a lower degree of blockage on the ebb tide than the flood tide.

\subsection{SEDIMENT TRANSPORT AND SCOUR}

Sediment transport is related to a high power of the velocity or shear stress (usually 3 to 5 for velocity or 2 to 3 for shear stress, Soulsby 1997). The outcome is that in any unit area of the seabed where the flow is accelerating and transport increasing there will be a tendency for net erosion of the seabed (scour) (Whitehouse, 1998). The opposite effect will be evident if the flow is decelerating (i.e. deposition). The flow, sediment and water depth control the sediment transport, and the structure interaction dictates the way in which the sediment transport deviates from the without-jetty case and how any scour develops.

\subsection{TIDAL ASYMMETRY}

The asymmetry in flood and ebb quantities can be interpreted as causing net sediment transport in either the flood or ebb direction (assuming the duration of both phases of the tide are comparable). When the ratio of peak flood velocity to ebb velocity is larger than 1 this indicates sediment transport is greater in the flood direction, whereas when the ratio is less than 1 then the net transport is in the opposite direction. Prior to the jetty being constructed the ratio (at the site of the jetty head) was predicted as lying between 1.6 and 1.7. The ratio increased 
rapidly towards the toe of the submerged cliff (values of at least 2.6), indicating that tidal asymmetry was more pronounced in the shallower water.

With the jetty in place the flood-ebb asymmetry adjacent to the jetty head still retains a value of 1.6 but varies spatially (Figure 6). The ratio of flood-ebb currents becomes as high as 2.0 in a band running north north-west from the jetty head and is reduced to much less than 1 in the shadow zone to the north of the jetty head and berthing dolphins 3 and 4 . To the south of the service platform and berthing dolphins 1 and 2 the ratio is larger than 3 . These changes from the pre-jetty situation will lead directly to local variations in the magnitude and direction of net sediment transport around the jetty.

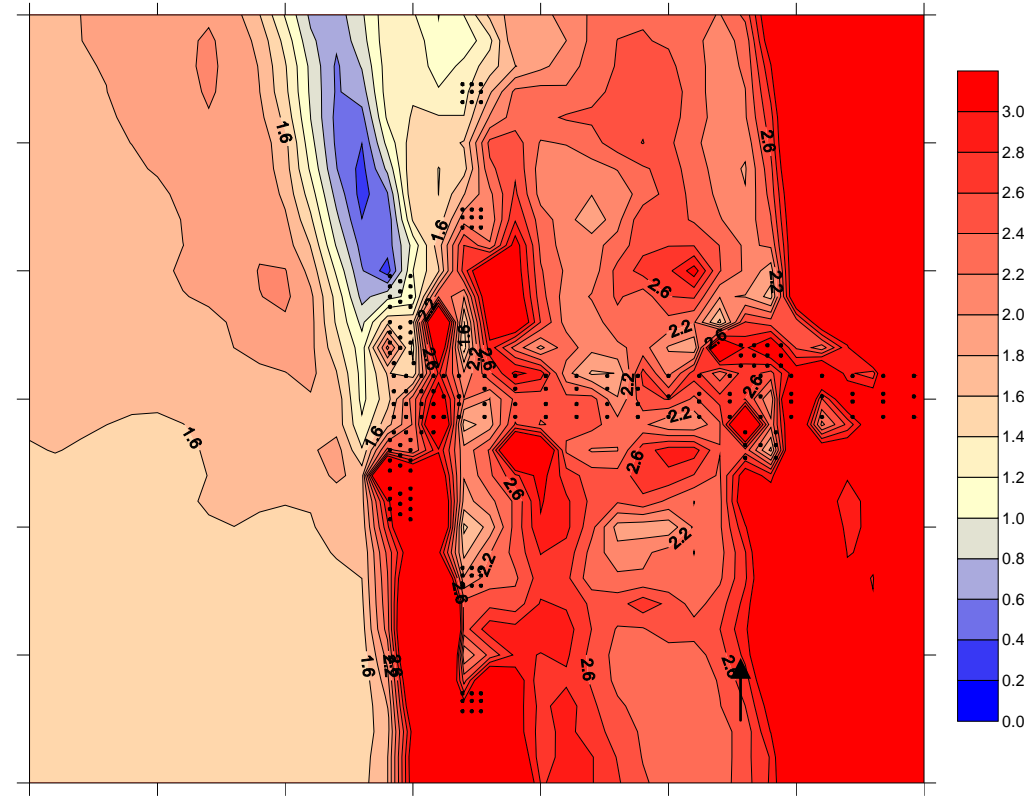

Figure 6. Flood-ebb velocity asymmetry with the jetty in place: $R$ bed velocity on flood tide to near bed velocity on ebb ti m spacing).

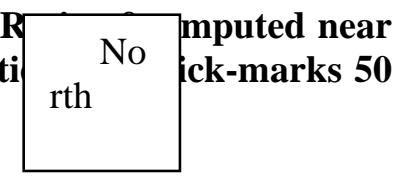

\subsection{INTERPRETING THE SCOUR DEVELOPMENT}

The modelled interaction of the flow with the jetty helps explain the detailed evolution of the bed in the areas where local scour has been observed and where reduced rates of erosion have taken place. The model results discussed above have been used to produce the interpretation diagram presented in Figure 7. The scour depth immediately around the piles was not measured but it is the global scour that was being assessed with both the survey results and the computational modelling. The change in bed level well away from the jetty, in particular offshore to the west, are likely to result from natural tidal processes. It is the combined effect of the regional and local change that causes the observed pattern of change. Part of the local scouring observed to the north of the jetty could result from the reduction in height of the bedforms observed in this area or a shift in the boundary between small and large sandwaves. 


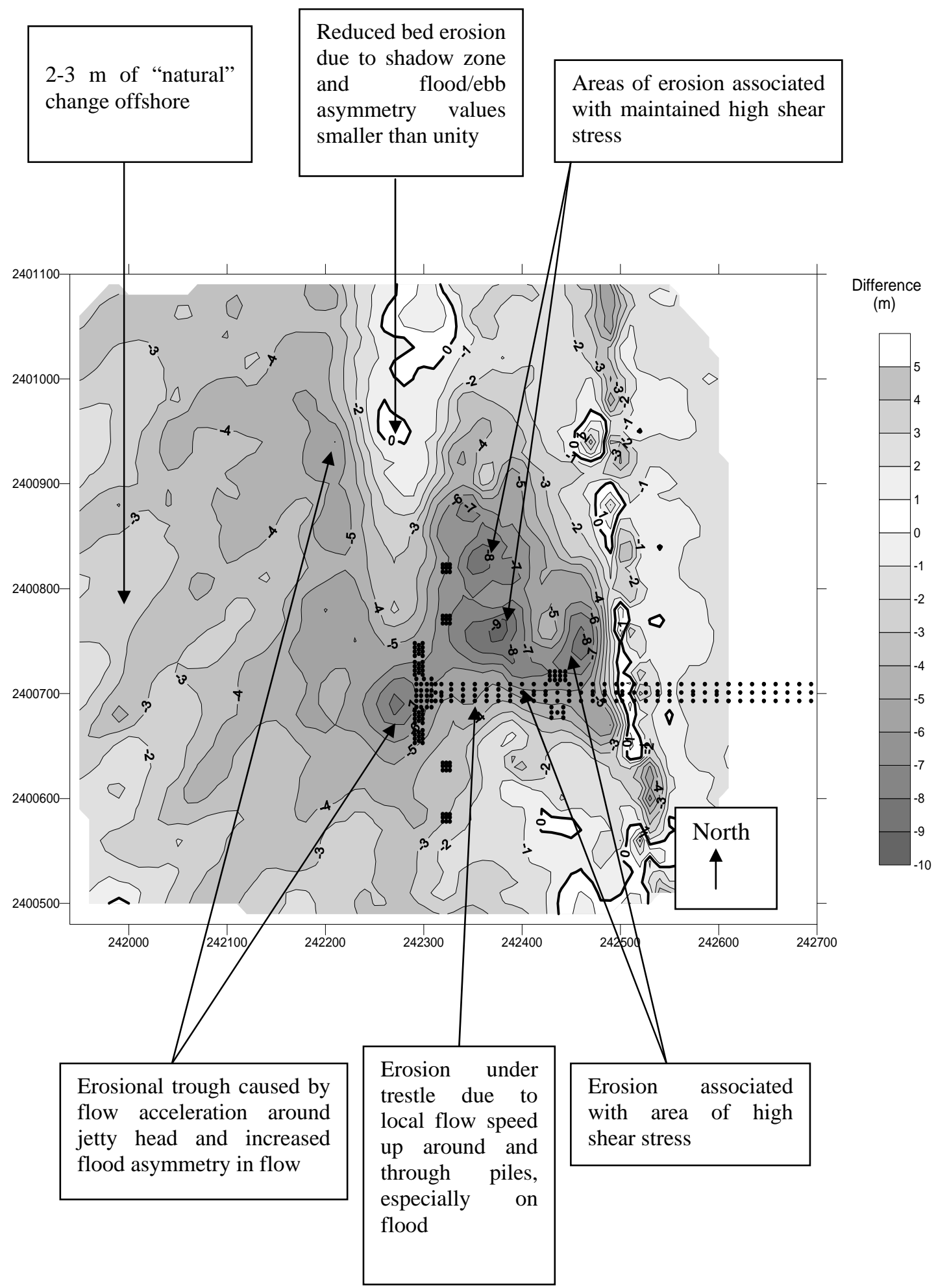

Figure 7. Interpreted bed level changes (post minus pre-construction levels) based on assessment of computational model results (local coordinate axes tick-marks $100 \mathrm{~m}$ spacing).

The mechanisms contributing to the observed bed level change arise from (1) local scour associated with the jetty structure, (2) lanes of fast flow and turbulence generation downstream of the jetty in the flood tide direction combined with the locally strong flood velocity 
asymmetry, causing (3) enhanced sediment transport and the migration of sandwaves over the seabed, and (4) regional scale erosion and deposition of sedimentary material which takes place naturally.

\section{CONCLUSIONS}

The CFD modelling approach described in this paper provides a flexible method and the high level of detail required when assessing the interaction of flows with complex piled marine structures. A detailed mesh was used to represent the main features of the pile array set within an accurate representation of the pre-construction seabed bathymetry. The model was set up with boundary conditions to represent the spatial and vertical distribution of steady-state peak flood and ebb tidal flow fields. The resulting flow speed and direction adjacent to the jetty head was compared with site measurements and found to be acceptable for the present assessment; predicted speed was within $10 \%$ of the measured value

Analysis of bathymetric survey data has shown local changes in seabed level around the jetty, with total maximum scour depths to the lee of the jetty on the flood tide of up to $9.5 \mathrm{~m}$ in three years and areas of siltation too. The CFD model was run both without and with the jetty in place to determine the flood and ebb tidal flow fields, turbulence and associated bed shear stresses. The nearbed velocity and shear stress are the driving force for sediment transport, and the changes in the pattern of these quantities directly informs the interpretation of the patterns of seabed scour and accretion. The development of the seabed scour pattern around the jetty could be explained from the pattern of flow, turbulent shear and bed shear stress with the jetty in place, and also the predicted asymmetry in flood-ebb flow speeds.

For other projects where complex piled structures are being considered for active sediment transport environments it is concluded that three-dimensional CFD modelling will provide a good diagnostic tool to assess the bed changes that will occur. Direct prediction of the depth of scour at these types of structures will require additional modelling effort and research.

\section{ACKNOWLEDGEMENTS}

The results of this study were published with kind permission of Skanska, Maple Cross, UK. Our colleagues Tom Stevenson and David Robinson plotted model results, John Baugh reviewed the draft version of this paper and the reviewers provided useful comments which we have addressed.

\section{REFERENCES}

Soulsby, R.L. (1997). Dynamics of Marine Sands. Thomas Telford Publications. 250 p.

Whitehouse, R.J.S. (1998). Scour at Marine Structures. Thomas Telford Publications. 216 p. 
NOTES 




\title{
Fluid thinking...smart solutions
}

HR Wallingford provides world-leading analysis, advice and support in engineering and environmental hydraulics, and in the management of water and the water environment. Created as the Hydraulics Research Station of the UK Government in 1947, the Company became a private entity in 1982, and has since operated as a independent, non profit distributing firm committed to building knowledge and solving problems, expertly and appropriately.

Today, HR Wallingford has a 50 year track record of achievement in applied research and consultancy, and a unique mix of know-how, assets and facilities, including state of the art physical modelling laboratories, a full range of computational modelling tools, and above all, expert staff with world-renowned skills and experience.

The Company has a pedigree of excellence and a tradition of innovation, which it sustains by re-investing profits from operations into programmes of strategic research and development designed to keep it - and its clients and partners - at the leading edge.

Headquartered in the UK, HR Wallingford reaches clients and partners globally through a network of offices, agents and alliances around the world.

\section{HR Wallingford}

Working with water

\author{
HR Wallingford Ltd \\ Howbery Park \\ Wallingford \\ 0xfordshire 0X10 8BA \\ UK \\ $\begin{array}{ll}\text { tel } & +44(0) 1491835381 \\ \text { fax } & +44(0) 1491832233 \\ \text { email } & \text { info@hrwallingford.co.uk }\end{array}$
}

www.hrwallingford.co.uk 